\title{
Overview of the Issue
}

\section{JEFFREY BROWN, MIKE ORSZAG and SYLVESTER J. SCHIEBER}

The last decade has seen tremendous interest in hybrid pension plans in the United States. These plans combine risk sharing between employers and employees with increased incentives for employees to remain in the labour force. Hybrid plans avert many of the key issues with defined contribution plans, such as participant exposure to financial risk, the consequent need for extensive financial education and high administrative costs. Hybrids also help rectify some of the main drawbacks of traditional final salary plans: lack of portability, high incentives to retire early and redistribution towards those whose wage growth is above average.

Yet despite these advantages, hybrid pensions have proven very controversial in the United States. At least some of the controversy is not about hybrid designs per se but about the process of converting from a defined benefit to a hybrid plan and whether the legislation adequately protects workers in the conversion process. In addition, hybrids are a relatively new form of provision and it has proven challenging to handle hybrid pensions within the existing U.S. regulatory framework. Further, it is clear to us that understanding of the features of hybrids is not as advanced as for more traditional forms of benefit provision.

It is to understand the US experience on hybrids that we have put together this special issue that is entirely composed of Issues \& Policy articles. Syl Schieber of Watson Wyatt Worldwide joins Jeff Brown and Mike Orszag as an editor of this special issue. Syl designed and selected the set of four articles that form this volume whereas Jeff Brown and Mike Orszag handled the review process.

The first article by Robert Clark (North Carolina State University) and Syl Schieber provides a broad overview of the evolution of hybrid pensions in the United States. There are two main types of hybrid pension plans: pension equity plans and cash balance plans. Clark and Schieber provide an overview of the design features of these plans, the motivation of corporate sponsors in switching to these plans as well as specific issues that have arisen such as "wear-away." On average, the move towards hybrid plans appears to be close to cost neutral for employers. However, there are distributional effects: in general, younger workers tend to receive higher benefit accruals under the hybrid plans whereas many older workers are worse off, particularly those who were counting on taking advantage of early retirement provisions.

The second article in this special issue is contributed by Julia Lynn Coronado (Federal Reserve Board) and Philip Copeland (Washington University). Coronado and Copeland use data from the S\&P 500 to look at the determinants of cash balance conversions. They find that there is some evidence that employers have converted to 
hybrid plans because of tax incentives that treat such conversions differently from a direct shift from a defined benefit to defined contribution plan. But they conclude that the conversions have been predominantly in competitive industries characterized by tight labor markets and highly mobile workforces. In such circumstances, the shift to hybrid plans could enhance the retirement security of workers relative to traditional defined benefit plans.

In the third article, Richard Johnson and Eugene Steurle (Urban Institute) look at the role of hybrid plans in an ageing population. As labour force growth slows in the United States, employers will have increasing demand for older workers. While the authors are far from suggesting that the move towards hybrids will induce a sufficient rise in labour force participation on its own, they do document in detail how the new hybrid designs help in this regard. Final salary plans in the US tend to encourage early retirement while existing hybrid designs have eliminated many of the early retirement subsidies.

Finally, Olivia Mitchell (Wharton School) and Janemarie Mulvey (Watson Wyatt) examine the costs if companies who made the transition to hybrid plans offered employees an option of remaining in the old DB plan. Mitchell and Mulvey estimate the cost to plan sponsors of such "grandfathering" provisions. They work with a database of employee data from 15 large companies that converted their traditional DB to hybrid plans since 1999 and offered related grandfathering provisions. A complication in terms of evaluating the costs of offering such a choice is the fact that many individuals do not make decisions predicted by economic theory. Nevertheless, the costs of offering grandfathering can be significant and this needs to be taken into account in the policy debate going forward.

This special issue is about hybrids in the US but there is clear interest in hybrid plans elsewhere in the world. Although hybrid plans are not common in the United Kingdom at present, there are a few recent examples and there is much interest in this topic. Pension structures in some countries such as Denmark, Netherlands and Iceland already have a fair degree of risk sharing in them. Looking forward, we would not be surprised to see risk sharing features emerge to address some of the limitations of some mandatory defined contribution systems through the world.

We hope you enjoy this special issue.

For news about forthcoming articles and other content, we encourage you to take a look at the Journal website (http://www.pensions-journal.com). 